\title{
Inhibition of Escherichia coli biofilm formation by Streptomyces sdLi crude extract
}

\author{
A.J. Neamah ${ }^{1}$, A.S. Al-Yassari' ${ }^{2}$, M.A. Hamed ${ }^{3}$ and M.A. AlRammahi ${ }^{4}$ \\ ${ }^{1}$ Zoonotic Disease Research Unit, College of Veterinary Medicine, University of Al-Qadisiyah, Al-Diwaniyha, ${ }^{2}$ Department \\ of Microbiology, College of Veterinary Medicine, Al-Qasim Green University, Babylon, ${ }^{3}$ Biotechnology and Environmental \\ Center, University of Fallujah, Anbar, ${ }^{4}$ Department of Physiology, Biochemistry and Pharmacology, College of Veterinary \\ Medicine, University of Al-Qadisiyah, Al-Diwaniyha, Iraq, Email: ${ }^{1}$ ahmed.neamah@qu.edu.iq, \\ ${ }^{2}$ abdul_kareem_al_yassari@vet.uoqasim.edu.iq, ${ }^{3}$ dr-moh75mnr@uofallujah.edu.iq, ${ }^{4}$ miran.alrammahi@qu.edu.iq
}

(Received July 26, 2019; Accepted September 09, 2019; Available online June 11, 2020)

\begin{abstract}
Biofilm is a microbial-protecting environment initiated on surfaces that reveals major health problems such as biofilms represented by dental plaques. Fighting biofilm formation is a hugely demanded process. Here, the crude extract of Streptomyces $s d L i$ (sediment lake Iraq-sdLi) was used to check the anti-biofilm formation bioactivity (ABFB) against Escherichia coli (Orooba Meteab Diwanyah 4, OMD4) isolated from milk samples. Using a cross-streak method, each strain of Streptomyces spp. was tested for the best broad-spectrum ABFB. A triplex polymerase chain reaction (TPCR) method targeted specific genes and a fragment (hemin receptor molecule (chuA), uncharacterized protein YjaA (yjaA), and chuA TspE4.C2) was used to categorize 18 isolated OMD4. Using the alcoholic extract of liquid growth of the best strain with ABFB, a crystal violet biofilm assay (CVBA) was employed to test the ABFB against OMD4. The results of the screening test revealed Streptomyces sdLi with strongest ABFB; however, ethyl acetate, as one of the $s d L i$ extracting solvents, was the most potent in in inhibiting the biofilm formation. The TPCR resulted in 18 isolates categorized into four groups A, B1, B2, and D in which B2 and D are known for their significant pathogenic activities in humans and animals. The results of the CVBA showed that Streptomyces sdLi extract was potential for its ABFB. This study recognizes that the Streptomyces sdLi extract is potential for deactivating biofilm formation by pathogenic E. coli which encourages future studies to consider this microorganism and/or its extract as a cure for the treatment of $E$. coli related illnesses in humans and animals.
\end{abstract}

Keywords: Biofilm, E. coli, Streptomyces, TPCR

DOI: 10.33899/ijvs.2019.125965.1202, @ 2020, College of Veterinary Medicine, University of Mosul.

This is an open access article under the CC BY 4.0 license (http://creativecommons.org/licenses/by/4.0/).

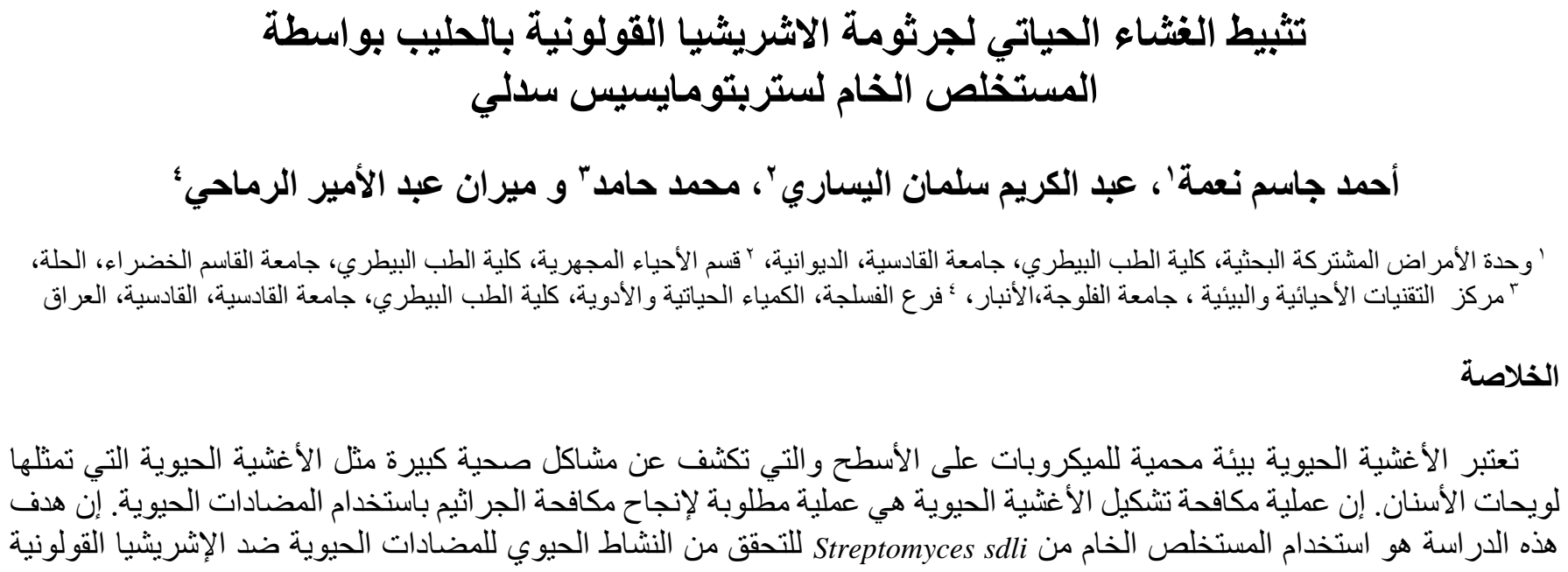


نوع OMD4 المعزولة من عينات الحليب. تم اختبار أربعون سلالة من .Streptomyces spp لأفل طيف واسع النطاق. استُخدمت طريقة

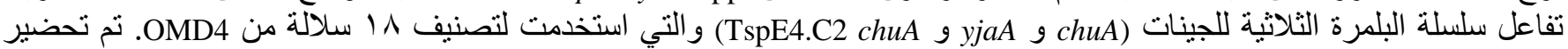

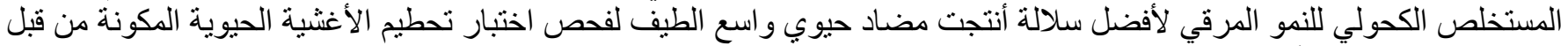

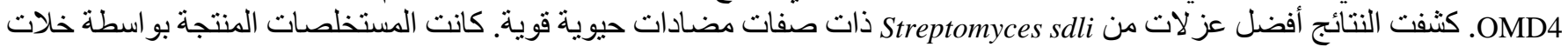

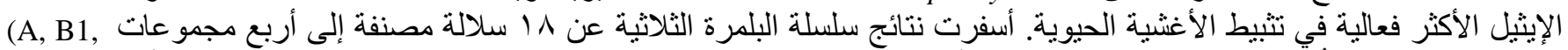

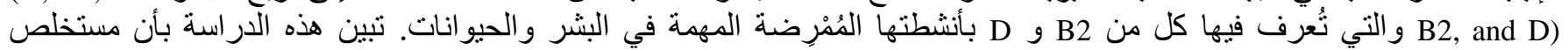
إجعل عtreptomyces sdli

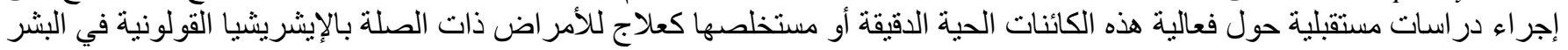

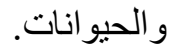

\section{Introduction}

The gram-negative bacterium, Escherichia coli, is microscopically known for its rod form. The lower-intestine located microorganism is categorized in the Enterobacteriaceae family. E. coli are arranged into wide spectra of genotyped groups that induce various human and animal illnesses of intra or extraintestinal diseases such as urinary tract infections (UTI). This pathogenicity is linked to E. coli specific virulence genes which ensure the completion of the infection processes including adhesion, colonization, bacterial proliferation, and fighting body defense mechanisms. Modern methodology relying on those virulence factor has improved understanding the groups of $E$. coli which basically are included in enteric/diarrheal illness group, UTI group, and sepsis/meningitis group (1-5). E. coli can affect humans via contaminated food such as milk, meat, and vegetables placing a critical public health problem. Whole milk or milk products are considered as an important media for bacterial growth which enhance the transmission of food-borne pathogens such E. coli (5).

Biofilm can broadly be defined as a bacterial ecosystem with complex nature initiated by bacterial attachment to a bacterial organic polymer matrix covered surface. The system also contains different microbial components with some substances of non-cellular origins such as mineral crystals. This system allows the microbial communities living within a biofilm to ensure homeostasis with each other and external environment. Biofilm structure is very complex and it strongly depends on the nature of the environmental niches in which a biofilm gets established (6). Biofilm formation enables microorganisms to escape and resist a wide range of substances such as antibiotics (7). It has been recognized that Streptomyces generate some metabolites which work against biofilm and the helping prokaryotic machine; quorum-sensing produced by Proteus mirabilis, UTI pathogen (8).

In the current work, the crude extract of Streptomyces $s d L i$ were used to check the anti-biofilm formation bioactivity (ABFB) against $E$. coli OMD4 isolated from the milk samples.

\section{Materials and methods}

\section{Sample collection of Streptomyces}

Iraqi river sediments and soil from various locations were used to collect Streptomyces. The samples were subjected to serial dilution processes using sterile water that reached up to $10^{-6}$. The cycloheximide-pretreated Actinomycetes agar (Difco) plates were inoculated with $0.1 \mathrm{ml}$ of the diluted solutions and incubated for 3-5 days at $29^{\circ} \mathrm{C}$. The growth was sub-cultivated by using tryptic soy broth (Oxoid, CM0129B) for purification purposes. The biochemical tests (starch hydrolysis, casein, glucose, sucrose utilization, lipid hydrolysis, citrate utilization, Rhamnose utilization, nitrate reduction, $\mathrm{H}_{2} \mathrm{~S}$ Production, and ability to grow in $8 \%$ ) were done to differentiate the microorganisms (9). As a screening test using a cross-streak method, each of 40 isolates of Streptomyces spp. was tested for the best broad-spectrum ABFB. The tryptic soy broth was used to sub-cultivate the microorganism to be centrifuged at $13,000 \mathrm{rpm}$ for $15 \mathrm{~min}$ and then harvesting the supernatant.

\section{Isolation of $E$. coli OMD4}

Eighteen milk samples collected form the healthy cows and cows with mastitis from different locations in AlDiwaniyah Governorate. Eighteen OMD4 isolates were detected by using the MacConkey agar (overnight incubation at $37^{\circ} \mathrm{C}$ ) and the Eosin Methylene Blue (EMB) agar. All biochemical tests were performed to identify the characteristics of the isolates.

\section{Extraction of bioactive substances of Streptomyces $\mathrm{s} d \mathrm{Li}$}

International Streptomyces Project (ISP2) media for streptomyces (selective media), yeast extract $4 \mathrm{~g}$, malt extract $10 \mathrm{~g}$, dextrose $4 \mathrm{~g}$, and agar $20 \mathrm{~g}$, was used to grow those microorganisms under suitable conditions for 9 days at $29^{\circ} \mathrm{C}$ of incubation with continuous shaking. The methods used in the current section were followed from Jensen et al. (10). The extract was constituted using $100 \%$ of dimethyl sulfoxide (DMSO) and kept at $4^{\circ} \mathrm{C}$ until further use in the anti-biofilm assay. For the fractioning of the extraction according to solvents used, bio-guided fractionation by using water 
solubilization before using diethyl ether, n-hexane, ethyl acetate, chloroform, and water had been done. Solventresulted layer was removed in three repeats of dissolving processes. After that, an evaporating step was performed before using $100 \mu \mathrm{L}$ DMSO as a carrier.

\section{Crystal violet biofilm assay}

The alcoholic extract was used as a liquid growth of the best strain with $\mathrm{ABFB}$, a crystal violet biofilm assay (CVBA) was performed to test the ABFB against OMD4 biofilm formation in urinary catheters. The cell density used was $1.5 \times 10^{7} \mathrm{CFU} / \mathrm{ml}$ treated with two concentrations of the extract $(10$ and $15 \mathrm{mg} / \mathrm{ml})$ plus using a no-treatment control. The mixture was placed in a 96-well plate pre-introduced with a $1 \mathrm{~cm}$-steralized piece of Foley catheter in each well. Then, the plate was incubated at $37^{\circ} \mathrm{C}$ for $24 \mathrm{~h}$. After that, a washing step with distilled water was performed, and a staining step by using $1 \%$ crystal violet was done followed by another washing step. Then, a re-solubilizing step utilizing $97 \%$ ethanol at $200 \mu 1$ was generated. After removing the liquid to another 96-well plate, the optical density (OD) was read at $595 \mathrm{~nm}$. A triplicate-based experiment was followed in the current study. Minimum inhibitory concentration (MIC) was tested. The same test procedures were followed to examine the activity of each solution extracted using different solvents.

\section{Extraction of DNA}

The DNA was extracted using a boiling method from Abdallah et al. (11). As an initiating process, $250 \mu 1$ of sterile distilled water was used to dissolve a few colonies of the OMD4 followed by a boiling method contained inoculated of $E$. an Eppendorf tube including a specific medium followed by an 18 hours incubation at $37^{\circ} \mathrm{C}$. The collected cells, then, centrifuged for $10 \mathrm{mins}$ at $6000 \mathrm{r} / \mathrm{min}$, which they were used in a heat-based lysis method. After removing the debris of the cells, the supernatant was used in a phenol/chloroform method.

\section{Triplex polymerase chain reaction}

Triplex polymerase chain reaction (TPCR) methods were followed from Clermont et al. and Gordon et al. $(12,13)$. The primers employed in the current study were used to detect the genes coding current as a chuA, yjaA, and TspE4.C2, are for ChuA (279bp); F: 5-GAC GAA CCA ACG GTC AGG AT-3` and R: 5`-TGC CGC CAG TAC CAA AGA CA-3`, for yjaA (211bp); F: 5-TGA AGT GTC AGG AGA CGC TG-3` and R: 5`-ATG GAG AAT GCG TTC CTC AAC-3`), and for TspE4.C2 (152bp); F: 5`-GAG TAA TGT CGG GGC ATT CA-3 and R: 5-CGC GCC AAC AAA GTA TTA CG3 . The total volume used for the PCR reaction was $25 \mu \mathrm{l}$ that contained PCR water at $11.25 \mu \mathrm{l}$, buffer at $2.5 \mu \mathrm{l}$ $10 \mathrm{X}$ (CinnaGen Co., Iran), $\mathrm{MgCl}_{2}$ at $0.75 \mu \mathrm{l}$ (CinnaGen Co., Iran), dNTPs at $1 \mu \mathrm{l}$ (CinnaGen Co., Iran), each primer at $1 \mu \mathrm{l}$
(20 pmol) (CinnaGen Co., Iran), Taq polymerase at $2.5 \mathrm{U}$ (CinnaGen Co., Iran), and DNA template at $3 \mu \mathrm{l}$. The conditions of the thermal cycler (MJ Mini, BIO-RAD-USA) were: $94^{\circ} \mathrm{C}$ for $4 \mathrm{~min}$ initial denaturation, 30 cycles of (denaturing for $5 \mathrm{sec}$ at $94{ }^{\circ} \mathrm{C}$, annealing for $10 \mathrm{sec}$ at $57^{\circ} \mathrm{C}$ ), and $5 \mathrm{~min}$ at $72^{\circ} \mathrm{C}$ of final extension. PCR products were separated through a $2 \%$ agarose gel using electrophoresis. UV light imager was used to screen the results on the gel.

\section{Results}

\section{Primary screening test}

The results of the strain identification revealed 18 Streptomyces strains. However, only Streptomyces sdLi crude broth showed the strongest ABFB against biofilm formation.

Minimum inhibitory concentration of the Streptomyces $s d L i$ extract against biofilm formation by $E$. coli OMD4

The MIC of the Streptomyces sdLi extract against biofilm formation by OMD4 was recorded to be $20 \mathrm{mg} / \mathrm{ml}$ (Figure 1).

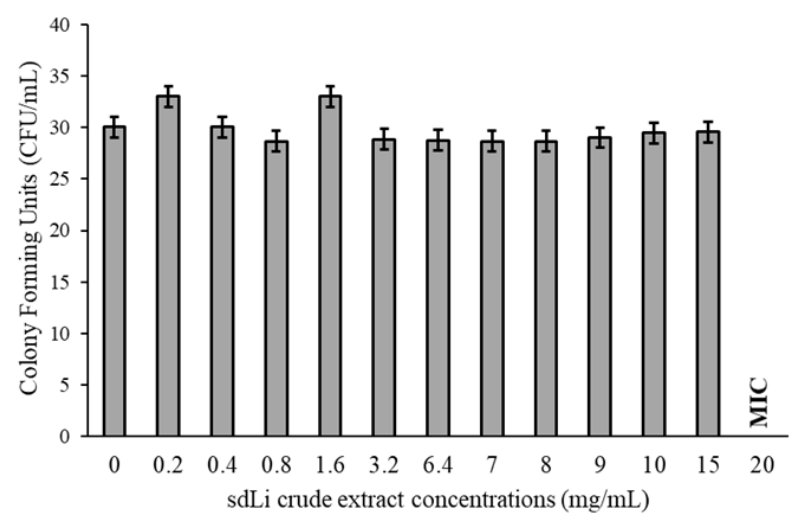

Figure 1: Colony forming unit on LB agar with the use of the spread plate method. Expression of each value was by mean of triplicates \pm standard deviation. Error bars (calculated from three repetitions) are also presented.

\section{Crystal violet biofilm assay using sdLi crude extract}

This study established a close relationship between inter bacterial communication and biofilm formation by OMD4 isolates. The untreated OMD4 isolate optical density (OD) reading on $595 \mathrm{~nm}$ wavelength was found out to be 2.900 (Figure 2.a). Based on figure (2.b), the OD reading of untreated OMD4 would form colonies above 30. It is therefore any wells that give 30 colonies or more can be considered to have no effect on growth with sdLi crude extract. Biofilm formation was reduced by $63 \%$ at $15 \mathrm{mg} / \mathrm{mL}$ sdLi extract. 


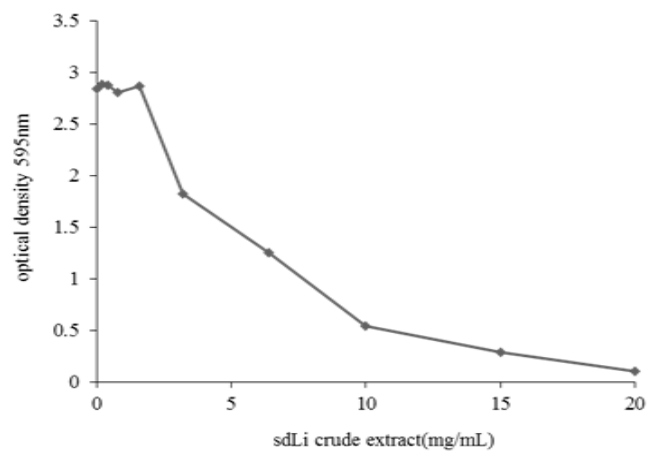

(a)

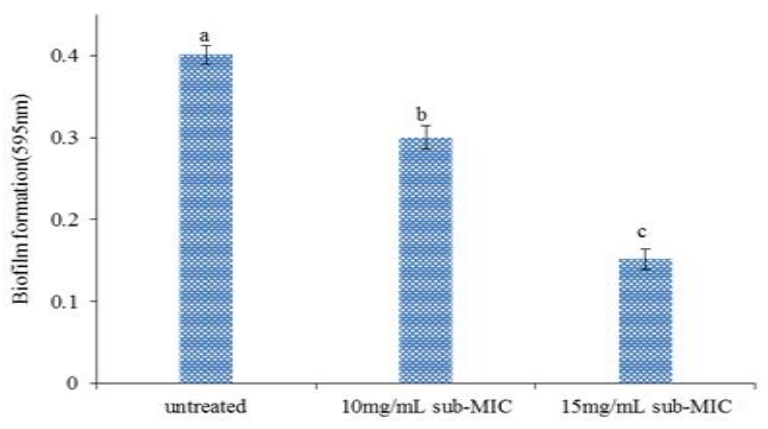

(b)

Figure 2: Effect of sdLi crude extract. (a) Different concentrations of sdLi extract effect on ECO4 read by optical density at $595 \mathrm{~nm}$. (b) Biofilm formation reduction. Significant difference $(p<0.05)$ was indicated by varying letters; a- b- c.

\section{The effects of the sdLi extracted on the biofilm formation according to the extracting solvents}

Ethyl acetate, as one of the sdLi extracting solvents, was the most potent in inhibiting the biofilm formation (Figure $3)$.

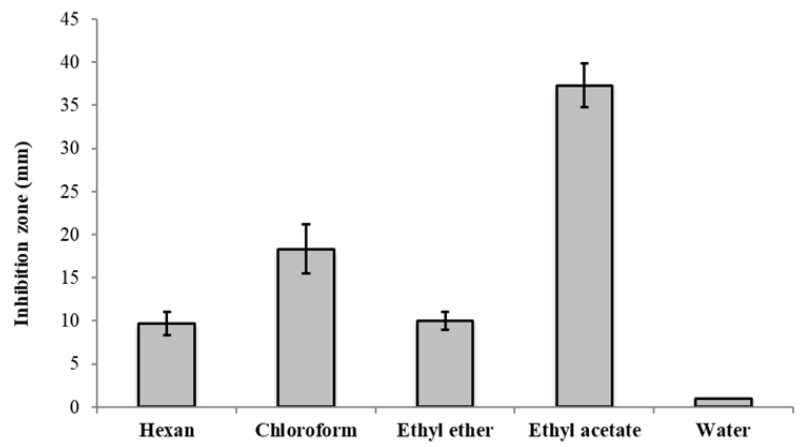

Figure 3: Inhibition zone according to the extracting solvents. Each value is expressed as the mean of triplicates \pm standard deviation and error bars (calculated from three repetitions)

\section{TPCR results}

The TPCR resulted in 18 strains categorized into four groups (A, B1, B2, and D) in which B2 and D are known for their significant pathogenic activities in humans and animals, figure 4 .

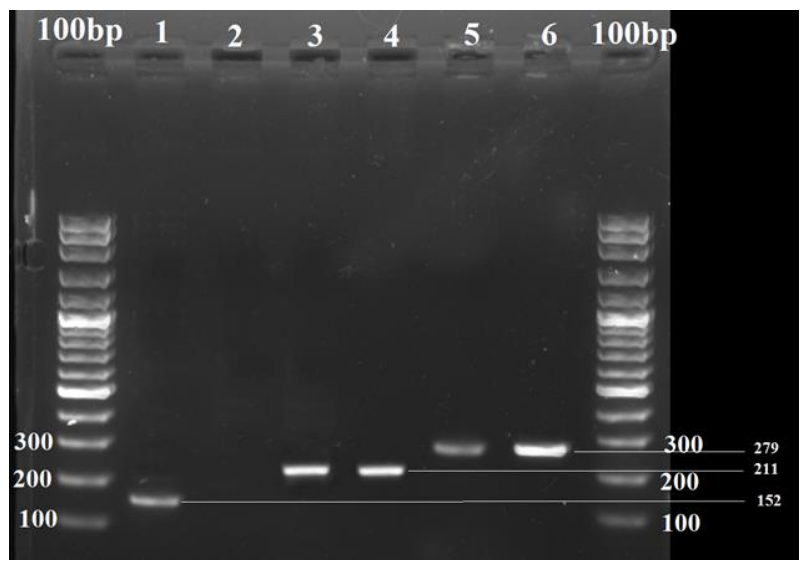

Figure 4: Agarose gel electrophoresis of lane 1: TspE4.C2 (152bp), lane 4: yjaA (211bp), and lane 6: chuA (279bp) genes.

\section{Discussion}

The TPCR resulted in 18 strains categorized into four groups A, B1, B2, and D. The groups B2 and D are known for their significant pathogenic activities in humans and animals. The extract of the sdLi was highly effective against OMD4 biofilm formation. This agrees with the fact that this extract was found to cause deactivation of virulence factors and significantly reduce forming of biofilm. The lowest concentration should be in the range of 10 and $15 \mathrm{mg} / \mathrm{ml}$. Further investigations should be launched in the future testing those concentrations for a deeper knowledge. The result suggests that the OD reading becomes lower when concentrations of the secondary metabolite extract are increased. Based on this, it can be inferred that the OMD4 biofilm formation has been inhibited. It has been proven that extracts can perform their beneficial duties, destruction of biofilm, without harming cells and thus agrees with our results; however, the pathogenicity and pathogen evolution can be strengthened via the formation of biofilm (14).

In quorum sensing of microorganisms, binding of a specific acyl homoserine lactone (AHL) signal molecules to a LuxR, regulatory proteins, is the first step in the quorum sensing induction. Disrupting this system via the inhibition of this step can provide vital solution in deactivating the biofilm formation (15). Compared to native AHL ligands, some cognate receptors have the capability to analogue-bind at higher rated affinity. However, the analogues then inactivate gene expression and therefore become antagonists 
$(16,17)$. Therefore, the results in this study suggest that the effect of the extract in a concentration-dependent manner to inhibit biofilm formation without effect on growth development is probably due to interference with native AHLs signals of cells and therefore become antagonists.

Marine microorganisms such as Streptomyces sp. OUCMDZ-3436 have been detected to have secondary products that can be highly effective against various bacterial activities and components such as quorum sensing after transforming the skeleton of $\alpha$-pyrone into pyridine- $2(1 \mathrm{H})$ one $(18-21)$.

\section{Conclusions}

The presented work here informs that Streptomyces $s d L i$ extracts have strong destruction activities against pathogenic E. coli isolated from milk samples. Furthermore, these actions are more dominant especially when using ethyl acetate as the main solvent. The observed functions against the biofilm structure may reveal promising medical interventions against a wide range of pathogens that use biofilm formation as a virulent tool to escape antimicrobials.

\section{Acknowledgments}

This study recognizes that the Streptomyces sdLi extract is potential for deactivating biofilm formation by pathogenic $E$. coli which encourages future studies to consider this microorganism and/or its extract as a cure for treatment of $E$. coli related illnesses in humans and animals.

\section{Conflict of interest}

We wish to draw the attention of the Editor to the following facts which may be considered as potential conflicts of interest and to significant financial contributions to this work.

We confirm that the manuscript has been read and approved by all named authors and that there are no other persons who satisfied the criteria for authorship but are not listed. We further confirm that the order of authors listed in the manuscript has been approved by all of us.

We confirm that we have given due consideration to the protection of intellectual property associated with this work and that there are no impediments to publication, including the timing of publication, with respect to intellectual property. In so doing we confirm that we have followed the regulations of our institutions concerning intellectual property.

We understand that the Corresponding Author is the sole contact for the Editorial process (including Editorial Manager and direct communications with the office). He/she is responsible for communicating with the other authors about progress, submissions of revisions and final approval of proofs. We confirm that we have provided a current, correct email address which is accessible by the Corresponding Author and which has been configured to accept email from (ahmed.neamah@qu.edu.iq, abdul_kareem_al_yassari@vet.uoqasim.edu.iq, @ drmoh75mnr@uofallujah.edu.iq, miran.alrammahi@qu.edu.iq).

\section{References}

1. Kaper JB, Nataro JP, Mobley HLT. Pathogenic Escherichia coli. Nat Rev Microbiol. 2004;2(2):123-40. doi: 10.1038/nrmicro818.

2. Allocati N, Masulli M, Alexeyev MF, Di IC. Escherichia coli in Europe: an overview. Int $\mathrm{J}$ Environ Res Public Health. 2013;10(12):6235-54. doi: 10.3390/ijerph10126235.

3. McClure PJ, Hall S. Survival of Escherichia coli in foods. Symp Ser Soc Appl Microbiol. 2000;14(29):61S-70S. doi: 10.1111/j.13652672.2000.tb05333.x.

4. Rahal EA, Kazzi N, Nassar FJ, Matar GM. Escherichia coli O157:H7Clinical aspects and novel treatment approaches. Front Cell Infect Microbiol. 2012;2:(138):1-7. doi: 10.3389/fcimb.2012.00138.

5. Donkor E, Aning K, Quaye J. Bacterial contaminations of informally marketed raw milk in Ghana. Ghana Med J. 2007;41(2):58-61. doi: 10.4314/gmj.v41i2.55302.

6. López D, Vlamakis H, Kolter R. Biofilms. Cold Spring Harb Perspect Biol. 2010;2(7):1-11. doi: 10.1101/cshperspect.a000398.

7. Koo H, Allan RN, Howlin RP, Stoodley P, Hall SL. Targeting microbial biofilms: Current and prospective therapeutic strategies. Nat Rev Microbiol. 2017;15(12):740-55. doi: 10.1038/nrmicro.2017.99.

8. Younis KM, Usup G, Ahmad A. Secondary metabolites produced by marine streptomyces as antibiofilm and quorum-sensing inhibitor of uropathogen Proteus mirabilis. Environ Sci Pollut Res Int. 2016;23(5):4756-67. doi:10.1007/s11356-015-5687-9.

9. Bergey DH, David H, Holt JG. Bergey's manual of determinative bacteriology. New York: Lippincott Williams \& Wilkins; 2000. 787 p. ISBN: 97806830060320683006037

10. Jensen PR, Williams PG, Oh DC, Zeigler L, Fenical W. Speciesspecific secondary metabolite production in marine Actinomycetes of the genus Salinispora. Appl Environ Microbiol. 2007;73(4):1146-52. doi: 10.1128/AEM.01891-06.

11. Abdallah KS, Cao Y, Wei DJ. Epidemiologic investigation of extraintestinal pathogenic Escherichia coli (ExPEC) based on PCR phylogenetic group and fimH single nucleotide polymorphisms (SNPs) in China. Int $\mathrm{J}$ Mol Epidemiol Genet. 2011;2(4):339-53. PMCID: PMC3243450.

12. Gordon DM, Clermont O, Tolley H, Denamur E. Assigning Escherichia coli strains to phylogenetic groups: Multi-locus sequence typing versus the PCR triplex method. Environ Microbiol. 2008;10(10):2484-96. doi: 10.1111/j.1462-2920.2008.01669.x.

13. Clermont O, Bonacorsi S, Bingen E. Rapid and simple determination of the Escherichia coli phylogenetic group. Appl Environ Microbiol. 2000;66(10):4555-8. doi: 10.1128/aem.66.10.4555-4558.2000.

14. Jamal M, Ahmad W, Andleeb S, Jalil F, Imran M, Nawaz MA. Bacterial biofilm and associated infections. J Chinese Med Assoc. 2018;81(1):711. doi: 10.1016/j.jcma.2017.07.012.

15. Hirakawa $H$, Tomita $H$. Interference of bacterial cell-to-cell communication: A new concept of antimicrobial chemotherapy breaks antibiotic resistance. Front Microbiol. 2013;4(114):1-14. doi: 10.3389/fmicb.2013.00114.

16. Hawver LA, Jung SA, Ng WL. Specificity and complexity in bacterial quorum-sensing systems. FEMS Microbiol Rev. 2016;40(5):738-52. doi: 10.1093/femsre/fuw014. 
17. Zheng Y, Sintim HO. Molecular insights into how ligands activate or inactivate LasR. Chem Biol. 2014;21(10):1261-3. doi.org/10.1016/j.chembiol.2014.10.001.

18. Storck P, Aubertin AM, Grierson DS. Tosylation/mesylation of 4hydroxy-3-nitro-2-pyridinones as an activation step in the construction of dihydropyrido[3,4-b] benzo[f][1,4]thiazepin-1-one based anti-HIV agents. Tetrahedron Lett. 2005;46(16):2919-2922. doi: 10.1016/J.TETLET.2005.02.128.
19. López SN. Chemically engineered extracts as an alternative source of bioactive natural product-like compounds. Nat Acad Sci. 2007;104(2):441-4. doi: 10.1073/pnas.0608438104.

20. Ramallo IA. Chemically engineered extracts: Source of bioactive compounds. Chem Res. 2011;44(4):241-250. doi: 10.1021/ar100106n.

21. Chen J. Quorum sensing inhibitors from marine microorganisms and their synthetic derivatives. Marine Drugs. 2019;17(2):80. doi: $10.3390 / \mathrm{md} 17020080$. 